\title{
Visual Culture and Spatial Infiltration: Modern Traditional Architecture of Fuzhou From the Perspective of Creative City
}

\author{
Yunqi $\mathrm{Li}^{1, *}$ \\ ${ }^{1}$ Fuzhou University of International Studies and Trade, Fuzhou, Fujian, China \\ "Corresponding author. Email: 494769780@qq.com
}

\begin{abstract}
The promotion of cultural and creative industries, the construction of creative cities and the attraction of creative classes can not only promote the reconstruction of urban space with cultural consumption capital, but also impact local cultural thinking, resulting in the alienation of urban space and cultural crisis. This article takes the current state of modern architecture and space in Fuzhou as an example, examining the possible deviation between the reconstruction of architectural ruins and the oblivion of traditional space places from the perspective of visual culture, with a view to reshaping a building protection that is truly connected to local culture and separated from the development ideology, and provide an analysis dimension for the architectural space paradigm of urban cultural capital deeply embedded in places and memories.
\end{abstract}

Keywords: visual culture, creative city, Fuzhou modern traditional architecture

\section{INTRODUCTION}

In terms of its occurrence, "visual culture" precedes the term "visual culture". The former is the condition and context in which the latter can be brought up. French philosopher Debord is one of the most critics of the cultural industry in continental Europe. In his book The Society of the Spectacle, he regarded the western modern society entering the age of consumption as a spreading "spectacle" image with commodity fetishes as the mode of daily life [1].The key to this spectacle is that it always understands activities based on the category of "seeing", thus establishing itself on the basis of technical rationality and infinite development. However, in this mode, the city faces gradually relate visual problems to cultural significance, forming a flood of terms such as "cultural creative industry", "cultural industry", "creative industry", "creative city" and "creative class". In recent years, the International Industrial Design Association has selected the Design Capital of the World every two years, and Taipei has taken this opportunity to win the reputation of the World Design Capital in 2016 by relying on the shaping of the cultural and creative park space. Therefore, through the promotion of creative cities and cultural creative industries, urban culture is transformed into the object of commodity consumption indirectly or directly, and such a carrier of cultural capital exists in a certain form of architectural space. In other words, creative cities are on the fast track of acceleration, and the architecture field is the first to respond and pose a huge impact on traditional regional production and life. On the one hand, the visual impact greatly stimulates the protection of architectural form and the city culture symbol capital hidden behind the symbolization; On the other hand, while the architectural form is preserved, its interior space is reshaped into a "free space" and a place for commodity trading, which is the core of modern architecture. Aboriginals live in environments without adequate natural and spatial memory, and their identity coordinates, self-expression and place memory are erased in the vigorous urban reconstruction [2].

The Fuzhou city concerned in this article was awarded the title of "Historical and Cultural City" by the State Council of China in 1986. Its history of building the city has been more than 2,200 years since the 5th year of the Han ancestors (202 BC). One of the first five cities in China to open ports, Fuzhou's early opening to the outside world made the stable "ceremonial" order of the city under the feudal system re-establish a complex and diverse urban space system between the mixed urban texture of the old and the new. This contains important historical information for the study of architectural history. When the modern urban structure of Fuzhou was gradually established after the 19th century, there was no comprehensive in modern commodity economy and industrial technology, the style of Fuzhou's traditional architecture and the Western classical style headed by Baroque coexisted in a "eclectic" state. Thanks to the group-like expansion of cities like riversides and coastal areas (See "Fig. 1"), 
most of these "eclectic" buildings are located in the areas of Cangqianshan foreigners' residence, Nantai Shangxiahang commercial area and Mawei Shipbuilding Industry In the area, the triad-style architectural space model of the old city of Fuzhou can still be maintained steadily. Therefore, while the urban area of Fuzhou City is expanding like riversides and coastal areas, the form of urban space formed by the building and the relationship between the base of the city map have also formed Mixed and split adjacencies (See "Fig. 2"). Therefore, on the basis of analyzing the characteristics of modern traditional architecture in Fuzhou, this article focuses on interpreting the relationship between the aesthetic characteristics of the architecture and the Fuzhou area and even the urban structure, and then re-examines the architectural shaping of Fuzhou's urban space by the architectural mechanism.

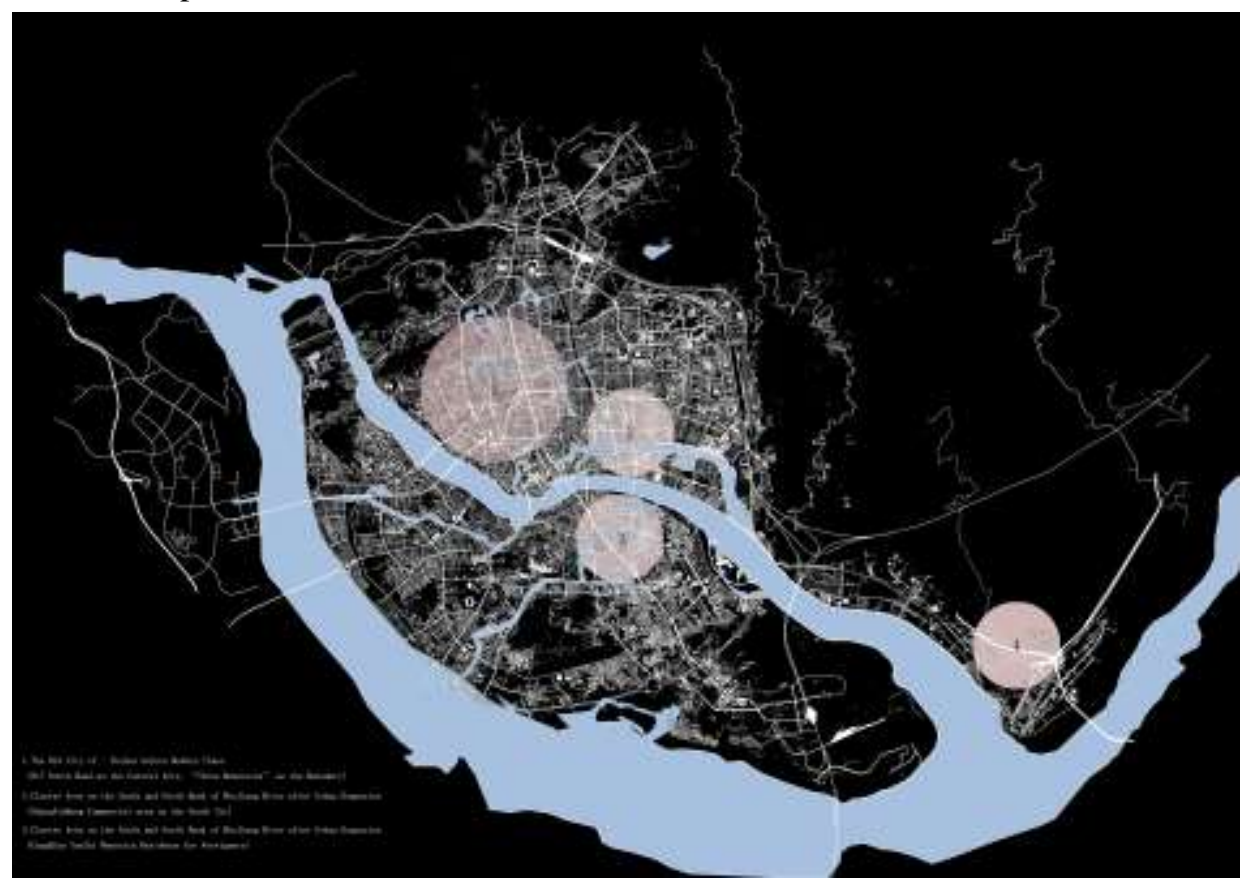

Fig. 1. The distribution of clusters formed in Fuzhou cities in modern times (1. Fuzhou Old City; 2, 3 North and South Banks of Minjiang River; 4 Mawei Shipbuilding Industrial Zone).
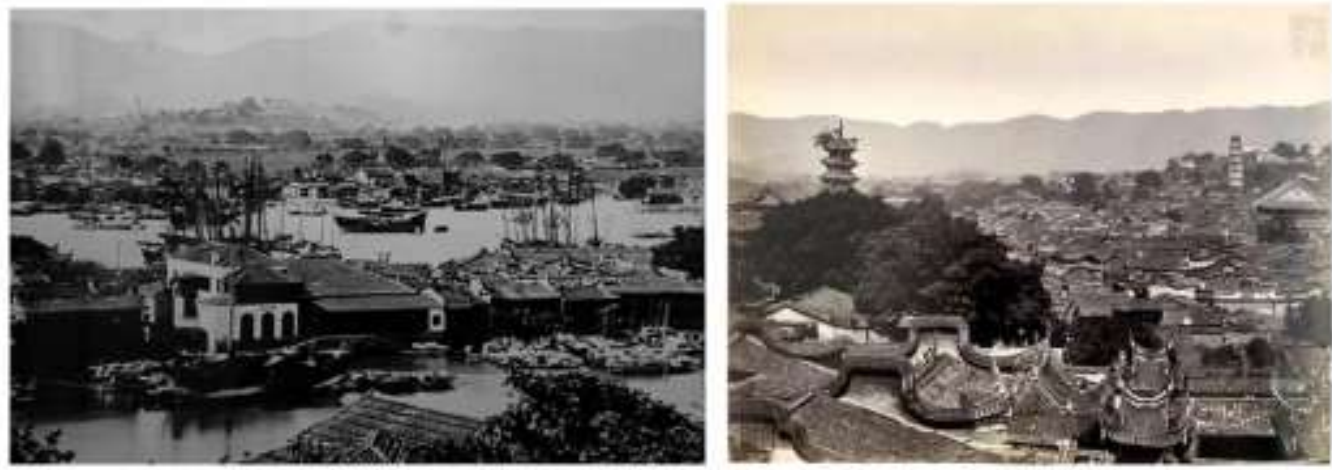

Fig. 2. The mixed architectural style on the banks of the Min River and the "continuous Fuzhou traditional houses" in the old city. 


\section{RETURNING TO MEMORY: ARCHITECTURAL AESTHETICS IN THE EVOLUTION OF FUZHOU'S MODERN URBAN STRUCTURE}

\section{A. The establishment of modern urban structure in Fuzhou}

Although the construction of Fuzhou city in ancient times did not have the name of "urban planning", the city layout was deeply rooted in the region according to the traditional ritual system, and it continued with the spatial system of more than 1,000 years from the song dynasty to the opium war in the late Qing Dynasty. Fuzhou's urban layout is based on the "geomantic theory" inherited from ancient Chinese urban planning. It has mountains and rivers on its back . and its central urban area is shielded by Pingshan. In front of it, Wushan and Yushan face each other(the picture on the right of figure 2 shows the scene of standing on the top of $\mathrm{Wu}$ mountain facing the $\mathrm{Yu}$ mountain in the central city), and it can be seen from the distance to the Yantai mountain on the south bank of the Minjiang river, which constitutes the urban border of the three mountains and two rivers of Fuzhou. The central city area also uses South Street as the central axis, and the two sides become lanes and alleys. It not only seeks "centering is positive" in Chinese traditional etiquette, but also adapts to the undulating mountainous terrain of Fuzhou. Fuzhou has been a political and cultural center in Fujian since the establishment of the county on the
Jin Dynasty. It is also known as the "Baozhong Blessing Land" because it is far from the Central Plains and avoids the scourge of war. Therefore, the ancient city of Fuzhou has a rigorous layout and good preservation.

The formation of the modern urban pattern of Fuzhou originated from the outbreak of the Opium War in the late Qing Dynasty. As the center of feudal society in China, Fuzhou has become one of the first five cities in modern China. During this period, Fuzhou's urban development ended the traditional "Capital city" and "Market city" separation. The development of Nantai Business District (now the Fuzhou Shangxiahang Historical and Cultural Preservation Area) has taken shape, and the formation of the Yantaishan Foreign Residency Construction Zone and Mawei Industrial Zone in front of the warehouse have established a modern city pattern in Fuzhou. Each area has different functions. The city still serves as a political and cultural center, retaining the features of the ancient city of Fuzhou; Shangxiahang area of Nantai is a commodity trade center; and the Cangqianshan area on the south bank of the Minjiang River is used as a residence area for foreigners. The building mainly constitutes the spatial appearance of the urban area. Therefore, the traditional architecture and the mixed buildings of China and the West are densely populated, presenting the multiple faces of Fuzhou opening to the outside world (See "Fig. 3").

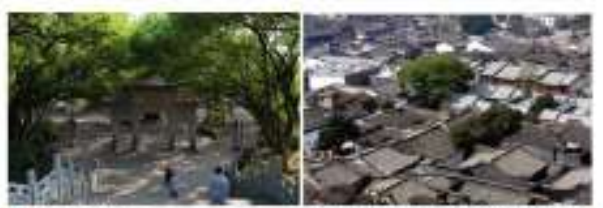

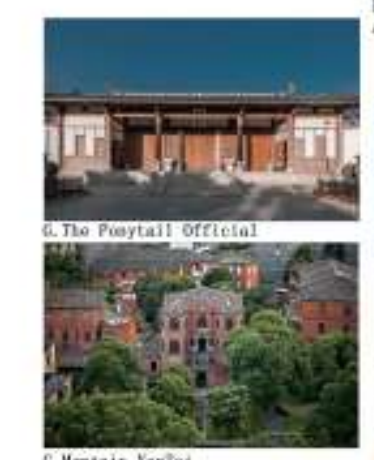

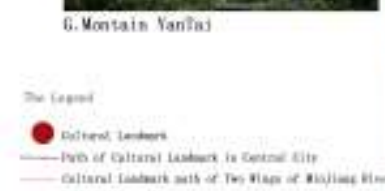

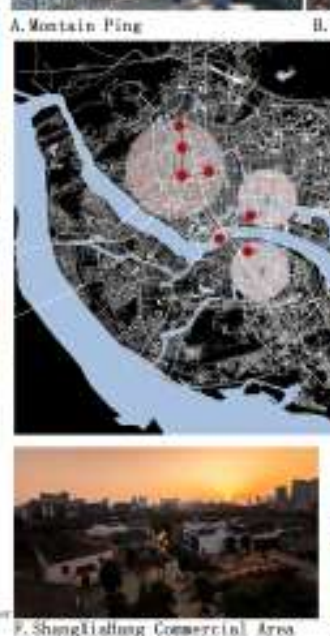

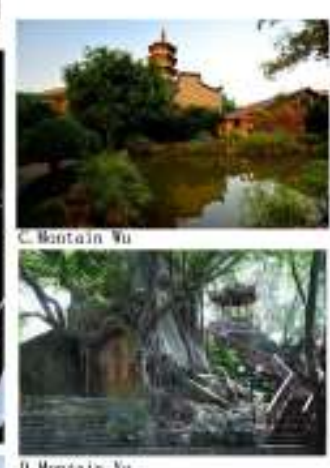

i. Muntaie Yu

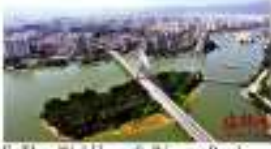

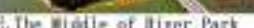

Fig. 3. Cultural landmarks in various key historical and cultural features of Fuzhou. 


\section{B. Architectural aesthetics in the evolution of modern urban structure}

After the opium war, Fuzhou was turned into a trading port. Faced with the transition from a traditional city to a modern city, the changes in the relationship between urban class, social division of labor and ideology have further expanded the spiritual value of architecture through materials. At the end of the 19th century, the typical representative of the transformation from Fuzhou traditional architecture to modern architecture was the appearance of "outer corridor" architecture and the tendency of eclectic style. The "outer corridor" building is also known as "colonial" building. Many of the early foreign consulate buildings in Fuzhou belonged to this category [3]. Since the early builders were mostly European and American colonists in Southeast Asia, it will be common in Southeast Asia. The introduction of architectural style into Fuzhou is a natural occurrence. However, because of the high permeability of the outer corridor buildings, the safety factor was low in the environment where xenophobia was high at that time. After the 20th century, the outer corridor buildings gradually became more Replaced by the pluralistic "eclectic house" .The prevalence of eclectic architecture in Fuzhou naturally stems from the prosperity of neo-classical and eclectic architecture in Europe at that time. The second is that Fuzhou, as a city with a solid economic foundation and a deep cultural tradition, is mostly built by local craftsmen in Fuzhou. Adapting to local conditions and using local materials has become a major feature of the building.

Therefore, the eclectic architecture can also be said to be the process of the spread and variation of foreign architectural culture in Fuzhou, resulting in the socalled "eclectic" architecture. As Fuzhou's traditional architectural aesthetics transformed into modern times, the "eclectic" also reconciled several conflicts. For example, the Gutian Guild Hall building in Fuzhou (See "Fig. 4"), as an important commercial building relic in modern Fuzhou, maintained the overall appearance of the folk houses in Fuzhou, and at the same time, a mixed arch appeared in the front facade of the front hall. The characteristic elements of traditional Chinese architecture, such as letters, plaques, couplets, traditional architectural door-ways and even leaky Windows, were also incorporated into the eclectic facade variations of modern western architecture in Fuzhou, such as ancient Roman style, gothic style, neoclassical style, art deco style and English style. In addition, the brick walls, stone structures, doors and Windows, and corridors of the main roof are western elements, and the volume and functions of the building space are more in line with the characteristics and practices of western architecture. Another is the continuous use of fire-proof gables in the houses of Fuzhou (See "Fig. 5"). Fuzhou's gables are different from the stepped horse-head walls in other areas of southern China such as Jiangsu and Zhejiang. More is smooth curve model, such as Yantai mountain, combining Chinese and western architecture, gable became to maintain overall characterization of the most important traditional building practices.

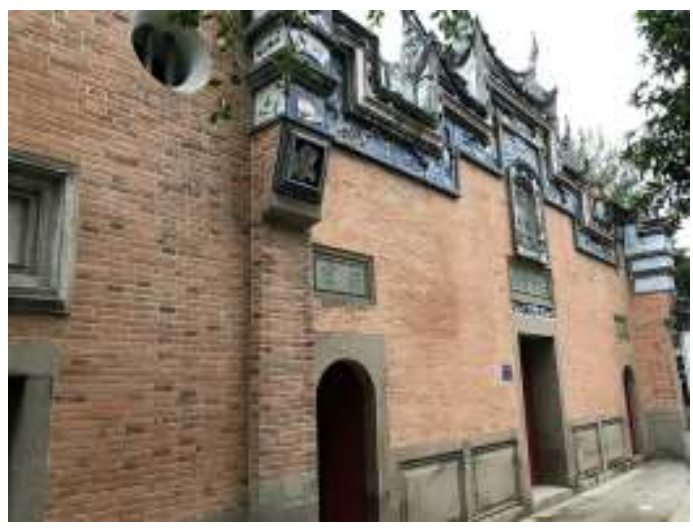

Fig. 4. Gutian Guild Hall Building.

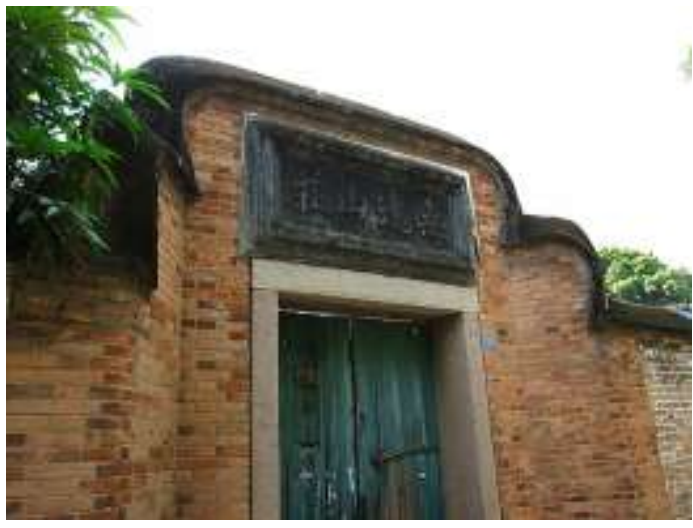

Fig. 5. Yantai Mountain Chinese-Western Building

\section{POST-MODERN SPACE INFILTRATION: REFLECTION ON THE STATUS QUO OF MODERN TRADITIONAL ARCHITECTURE UNDER THE HISTORICAL AND CULTURAL STYLE AREA}

\section{A. Three lanes and seven alleys historical cultural feature area: construction of architectural culture and forgetting of place space}

Just like the temple of Athens and Notre Dame cathedral in Paris, as well as the Forbidden City in Beijing and the Gardens in Suzhou, Three Lanes and Seven Alleys are the most important name card of Fuzhou. Before the opening of Fuzhou in the late Qing Dynasty, it was the innermost area of the inner city that symbolized the urban pattern of Fuzhou's "North City" and "South City". Since Fuzhou descended from the Han Dynasty, the city has expanded from north to 
south, with Pingshan as an obstacle. Yushan and Wushan face each other to form Fuzhou's most important inner city pattern. The city is divided into "North City" and "South City" by "political aristocracy center" and "civilian merchants". The North City takes South Street (now Bayi Qi Road) as the central axis, and the two sides of the central axis are arranged in alleys and lanes, which are symmetry-oriented. A scholar-official class, cultural class as the main aboriginal areas of the "Three Lanes and Seven Alleys" formed. In addition, the original city center of Fuzhou, with Three Lanes and Seven Lanes as the core, formed a landscape city face of "Three Mountains and Two Towers" facing "Minjiang River and Wujiang River", and the continuous Fuzhou gable wall constructed the picture memory of the early capital of eastern Fujian in the urban bosom of Three Mountains and Two Towers (See "Fig. 6"). This portrayal of the spirit of the city is more concentrated in the space of Three Lanes and Seven Alleys. The Lanes still retains more than 200 ancient Ming and Qing architectures, with turquoise roofs, white powder walls, bluestone slabs, and The alleyway in the stone-paved road, the rockery, the flower hall, the fish pond, and the pavilion in the Ming and Qing architectural courtyards once attracted a large number of modern celebrities to live here. It shows the symbolic status of the urban elite culture and the urban places of Fuzhou that have been integrated for generations (See "Fig. 7").

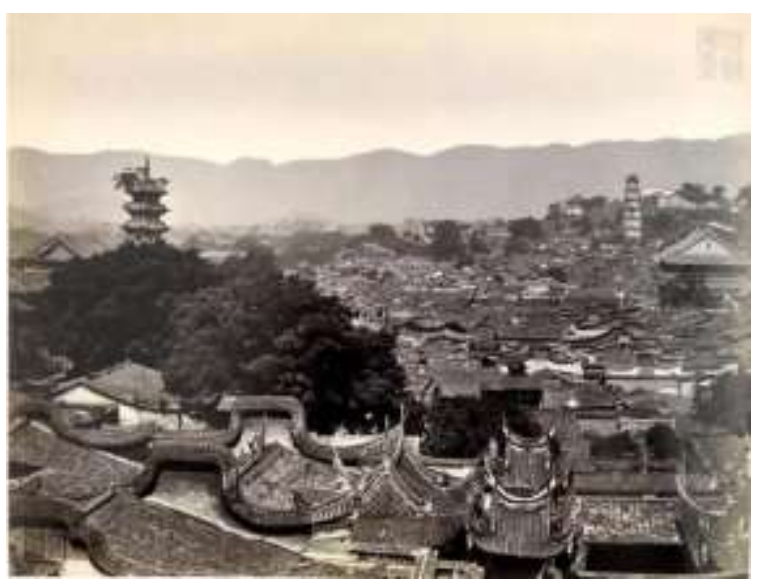

Fig. 6. It is rumored that this picture shows the scene of Fuzhou city shot by American missionaries standing on the top of Wushan Mountain and looking at Yushan Mountain.

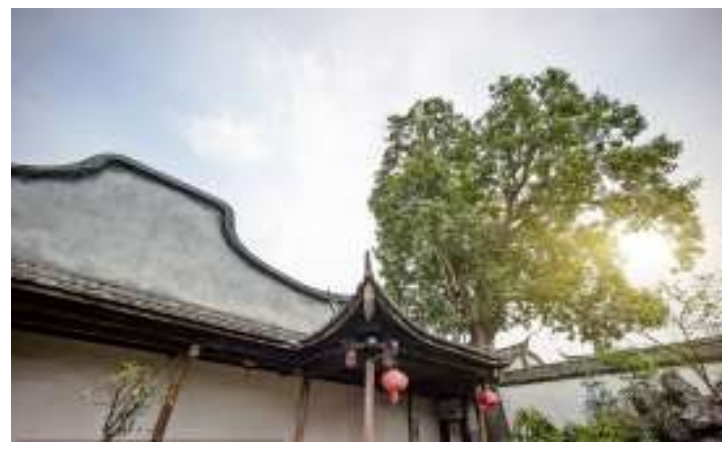

Fig. 7. A residential courtyard in "Three Lanes and Seven Alleys".

However, in the post-modern consumer society, "capital city" and "market city" are no longer separated by space, and Three Lanes and Seven Alleys has also changed from a field where scholars and elites gather to being composed of continuous growth, service, and material wealth. A place for amazing consumption and a rich material world. Just as the Society of the Spectacle understood by Debord based on the category of "seeing", the cultural value of Three Lanes and Seven Alleys has to enter the commercial capital operation with the cultural symbol capital of "Museum of Ancient Buildings of Ming and Qing Dynasties" and "Living Fossil" of the urban square system. On the one hand, it is the protection of ancient architectural sites. In 1993, Hong Kong Cheung Kong (Holdings) signed a contract with the Fuzhou Municipal Government to implement real estate transformation on the part of Yijin Lanes in Three Lanes and Seven Alleys with a development strategy. By 2003, the project completed four 13-storey high-rises in Three Lanes and Seven Alleys, forming a new residential area dominated by high-rise residences, which directly led to the lack of the northern interface of Yijin Lanes, one of the most famous lanes in Three Lanes and Seven Alleys. Affecting the overall "skyline" of Three Lanes and Seven Alleys. This project was subsequently stopped by the Fujian Provincial Government. The protection of Three Lanes and Seven Alleys was revised to the south in the "Protection Planning of Three Lanes and Seven Alleys Historical and Cultural District" in March 2007. Old shops on both sides of the back street were rebuilt with "antique" architectural features, and architectural sites such as celebrities' former residences were renovated as usual, relying on the brand effect of Three Lanes and Seven Alleys to introduce dining features outside the region, and drive the district's vitality with tourism culture; On the other hand, while the governance of the building is being protected, The "elite culture" inherited for thousands of years has evolved into a "snack street" with simple culture externalization without the symbolic elements of indigenous people and local production and life. Three Lanes and Seven Alleys Protection and Development Co., Ltd. introduced the elements of cultural creativity 
to create a" creative city "concept. Three Lanes and Seven Alleys Conservation and Development Co., Ltd. introduced the elements of cultural creativity to create the concept of "creative city", and finally transformed it into coffee milk tea, postcards, greeting cards, and handbooks around it. Fuzhou city spirit formed by scholars and cultural celebrities and even modern Chinese history the spirit is completely dissipated (See "Fig. 8").
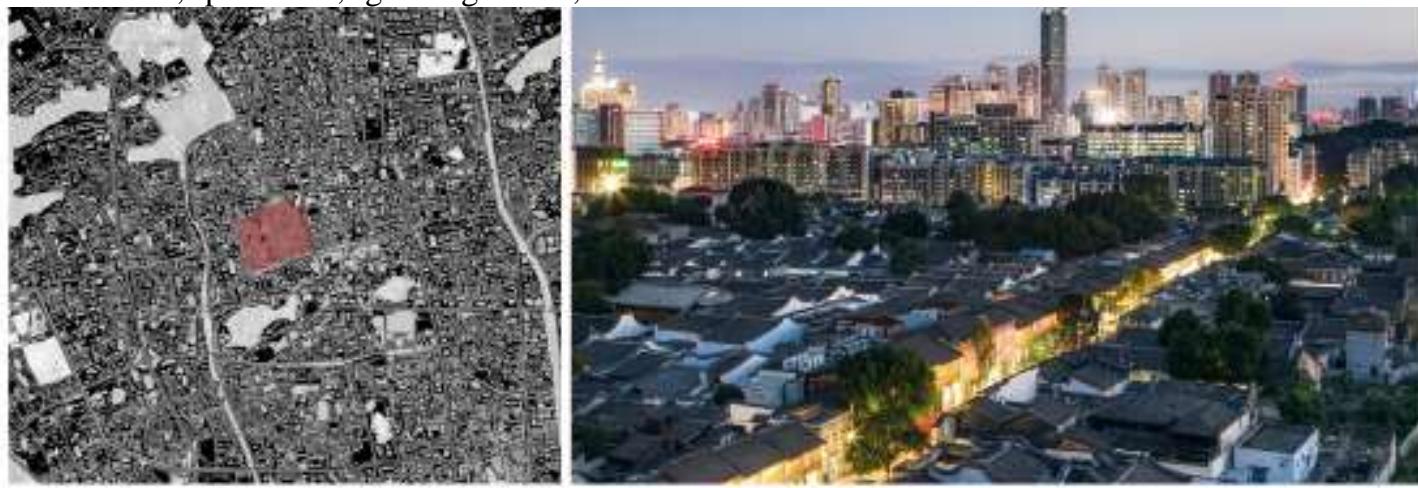

Fig. 8. Relationship between Three Lanes and Seven Alleys and Fuzhou urban texture.

\section{B. Shangxiahang, Yantai Montain historical and cultural style area: windows of space and architectural symbols}

Nantai Shangxiahang and Yantai Mountain historical cultural area, the former commonly known as "Double Hang", which refers to the Taijiang Shanghang Road and Xiahang Road, "Hang" is actually "Shipping" sound derived, which is related to the historical process of geographical changes. In ancient times, the water of the Minjiang River bypassed the Diaomiao Mountain, and Shangxiahang was the port of Jinkou. This ancient block, once famous for its prosperous commerce, has been an important place for folk customs and historians to study the commercial development of Fuzhou. Since modern times, many provincial and municipal Chambers of commerce have gathered in Shangxiahang, hence the name of "Fuzhou traditional commerce museum" (See "Fig. 9"). The latter is a Yantai Montain foreigner's residence where foreigners enjoy a little privilege due to the "Jiang Ning Treaty" signed by Fuzhou City in 1842. In 1855, with the permission of the Qing government, the British consulate established a base of consular office in front of the warehouse. Since then, consulates and merchants from various countries have rented land in front of the warehouse to build foreign firms, mansions, churches, schools, hospitals, racecourse, etc. Yantai Mountain was thus named the "exhibition of all nations' architecture" (See "Fig. 10") [4]. Therefore, in the modern Fuzhou, a larger range of "Northern City and Southern City" (Northern City refers to the original urban area of Fuzhou, that is, an area where political culture and elite culture are gathered, and Southern City is above Shangxiahang and Yantai Mountains as a model. The estuary of Minjiang River forms a mixed Chinese and Western bazaar). Such complex, continuous and active social activities and the organized urban spatial pattern have formed a more diverse and delicate and modern traditional architecture in Fuzhou. The Gutian Guild Hall Building mentioned above is located in Shangxiahang area. As a commercial guild hall, the architecture of the Gutian Guild Hall integrates mazu culture, a symbol of "boat people's belief", and the traditional ancient folk houses in Fuzhou. It is also blended with western classical style on some doors, Windows and architectural elements. In the "eclectic architectural aesthetics" dominated by the foreign culture of Yantai Mountain, on the level of complete westernization of form, the Chinese method of water brick processing was applied to decorate the linings of western classical architecture, and the large area of rolling Fuzhou traditional gable appeared in Yantai Mountain foreign house architecture. Just as Fei Xiaotong once said, "our nation grew up in the earth. The earth has had a glorious history." [5] Fuzhou once formed an unmovable cultural foundation due to the stability of its locality. Even in the modern times when western culture was strongly implanted, the buildings directly attached to the soil still took root like plants, giving birth to the local thinking and regional urban society "Born here, grow here". So when "Shangxiahang, Yantai Mountain and Three Lanes and Seven Alleys", aimed to introduce cultural creative elements, its fundamentally from urban culture foundation, in the name of "concept" is the transplantation of the same business model, "Northern city and Southern city", "Three Mountains and Two Towers", modern traditional architectural aesthetics in the north and south Banks of Minjiang River, traditional modern architecture including continuous in the vision of the city memory gable, with "creative cities" intervention, the urban skylines of the capital of 
eastern Fujian and the multifaceted city of Fuzhou are far from memories.

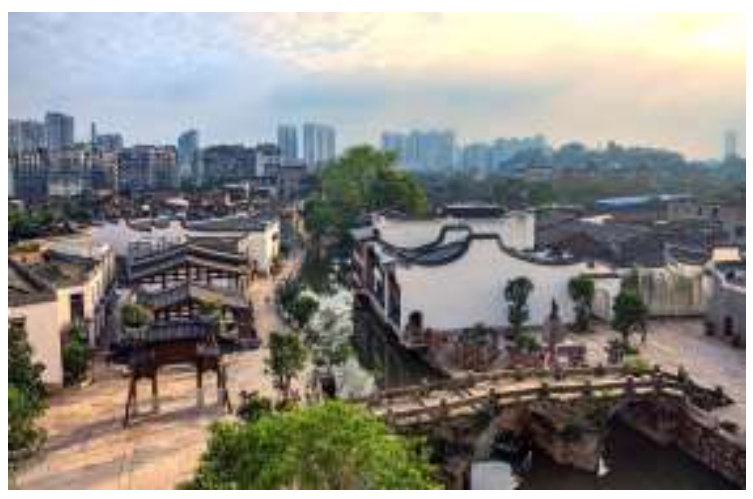

Fig. 9. Shangxiahang after transformation.

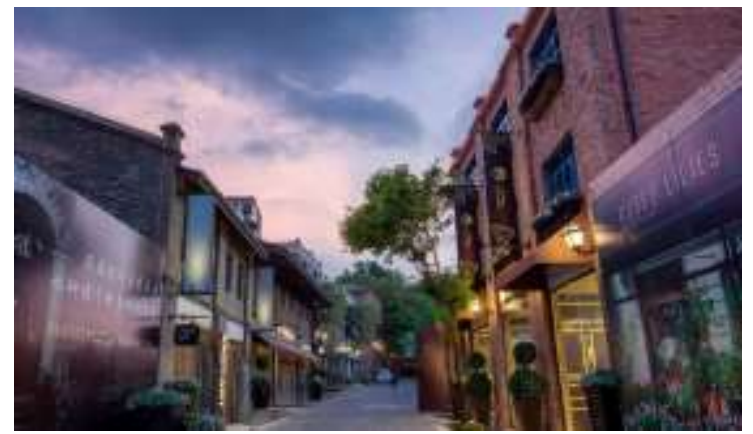

Fig. 10. Yantai Montain after transformation.

\section{CONCLUSION}

South Back Street archway of Three Lanes and Seven Alleys in the late Qing dynasty Wan Guorui once made a couplet: "Guests sneak away from the book market, but I haven't seen enough." The Guangzhou poet described the scene where South Back Street is the concentration of ancient bookstores in Fuzhou. Today, the lanes are crowded and bustling, but together with historical and cultural protection areas including Shangxiahang and Yantai Montain on the north and south banks of the Minjiang River, they often fall into self-myths in the simple consumption trend of "heterogeneity". Three Lanes and Seven Alleys, Nantai Shangxiahang and Yantai Montain are no longer used as a symbol of Fuzhou's "Northern City and Southern city". The vigorous cultural city-building movement broke the commodity logic and quickly connected the architectural cultural heritage as a readable symbol Consumer space discussion topics. However, this paper is not intended to analyze the image itself of the regional development of Fuzhou's modern city comprehensively, but only to ask questions about the presence of the urban and architectural elements just existing in the historical images: "Fuzhou was previously centered on Bayi Qi Road. With the three mountains as the boundary, and spreading to the multiple mixed landscapes of the Minjiang River, how can a 'differential pattern' of urban space spread out from points be reduced to a cultural window under the vision of a creative city? If we cannot deeply evoke the local thinking of the aboriginal spatial memory and architectural protection, then rather than finding a deep connection between the historical and cultural city and urban modernity, it is better to just glimpse the architectural meaning in its visual scenery."[6]

\section{References}

[1] Guy Debord,The Society of the Spectacle [M], Nanjing: Nanjing University Press, 2018.11.

[2] Xu Jing, Culture and Space: The Transformation and Reflection of Urban Cultural Capital in the Revival Practice of Historic Districts: A Case Study of Three Lanes and Seven Alleys, Fuzhou City $[\mathrm{J}]$. Journal of University of Science and Technology Beijing (Social Science), 2019, 35 (03): 82-88.

[3] Zheng Junzheng, Zhu Yongchun. Variations of Modern Traditional Architectural Forms in Fuzhou [J]. Journal of Fuzhou University (Natural Science Edition), 2005 (05): 628 632.

[4] Xue Ying. Fuzhou residential land construction in the second half of the 19th century $[\mathrm{J}]$. Chinese and Foreign Architecture, 2004 (03): 85-87.

[5] Fei Xiaotong, Hometown China [M], Beijing:People's Publishing House, 2015.04.

[6] Li Yunqi, Wu Shaoping. Translation of Narrative Expression of Contemporary Art Curatorial Exhibition in the Design of Homestay [J]. Decoration, 2008, 10: 106-108. 